\title{
Evaluation of Tadalafil effect on lower urinary tract symptoms of benign prostatic hyperplasia in patients treated with standard medication
}

\author{
Ali Hamidi Madani, Amin Afsharimoghaddam, Ali Roushani, Alireza Farzan, Ahmad Asadollahzade, \\ Maryam Shakiba
}

Urology Research Center, Guilan University of Medical Sciences, Iran

\section{ABSTRACT}

Objectives: To evaluate safety and efficacy of tadalafil on lower urinary tract symptoms (LUTS) suggestive of benign prostatic hyperplasia (BPH) in patients treated with standard medication.

Materials and Methods: In this case-controlled randomized clinical trial, from November 2008 to August 2009, 132 patients with obstructive and irritative urinary tract symptoms due to BPH, IPSS $\geq 8$, no indication for surgical intervention and that reached plateau levels of response to treatment were selected. These patients were randomly allocated in two groups (each containing 66 patients). The treatment group received standard treatment of BPH and tadalafil (10 mg nightly); the placebo group received only standard treatment of BPH. IPSS, maximum urinary flow rate $\left(Q_{\max }\right)$ and quality of life were assessed before and after a 3-month period of study. Results: Before treatment, mean IPSS, $\mathrm{Q}_{\max }$ and quality of life values in the treatment and placebo groups were $13.06 \pm 4.37$ and $13.66 \pm 4.25,8.92 \pm 2.96 \mathrm{~mL} / \mathrm{s}$ and $9.09 \pm 2.91 \mathrm{~mL} / \mathrm{s}, 2.93 \pm 0.86$ and $2.66 \pm 0.78$, respectively. After treatment, mean IPSS, $Q_{m a x}$, and quality of life values in treatment group were $7.66 \pm 3.99$, $9.99 \pm 4.76 \mathrm{~mL} / \mathrm{s}$ and $1.80 \pm 0.98$, respectively. These findings were compared to corresponding values of the placebo group $(11.37 \pm 3.64,8.73 \pm 2.22 \mathrm{~mL} / \mathrm{s}$ and 2.19 \pm 0.53 , respectively): IPSS and quality of life were significantly different but $Q_{\max }$ didn't show a significant change.

Conclusions: Tadalafil improves quality of life and urinary symptoms in patients with LUTS suggestive of BPH, but doesn't have any significant effect on Qmax. Therefore, this drug may be effectively used in combination with standard medical therapies for BPH.

\section{ARTICLE INFO}

\section{Key words:}

Tadalafil; benign prostatic hyperplasia; quality of life; prostate; erectile dysfunction

Int Braz J Urol. 2012; 38: 33-39

Submitted for publication: November 03, 2010

Accepted after revision:

October 24, 2011

\section{INTRODUCTION}

Benign Prostatic Hyperplasia (BPH) is a pathological process responsible for the majority of lower urinary tract symptoms (LUTS) in elderly men (1). In addition, erectile dysfunction (ED), which has negative effect on quality of life (QoL), is another major problem of this age group (2).
The incidence of BPH increases with age. It is observed in about $50 \%$ of men over 50 year with prevalence increasing up to $90 \%$ in those older than 80 year. Moreover, 25\% to 50\% of men with histological confirmed BPH have LUTS (3).

The $\alpha$-blockers and/or 5- $\alpha$ reductase inhibitors are used for the treatment of BPH frequently. The phosphodiesterase inhibitors are 
used in the treatment of ED $(4,5)$ and there are increasing data of effects of these drugs on bladder and urethral relaxation as well as of prostatic smooth muscles that may relief the symptoms of BPH $(6,7)$. Preliminary data have suggested that treatment with PDE-5 inhibitors such as sildenafil improves LUTS in men with ED possibly as the result of smooth muscle relaxation of the lower urinary tract (8).

This study was conducted to evaluate the role of Tadalafil (a PDE-5 inhibitor) in combination with standard therapy for the treatment of $\mathrm{BPH}$.

\section{MATERIALS AND METHODS}

This study was a randomized doubleblind placebo controlled clinical trial which has been approved by the ethical review board of Guilan Medical University. All patients signed an informed consent to participate.

In the beginning of the study, 132 patients with definitive diagnosis of BPH whose response to medical therapy with standard medication had reached plateau levels (the symptoms of patients didn't change in the last three months) were selected. In the placebo group, 23 patients received an $\alpha$-blocker and 43 patients received an $\alpha$-blocker plus Finasteride, as well as placebo. In the treatment group, besides Tadalafil, 16 patients received an $\alpha$-blocker and 50 patients received an $\alpha$-blocker plus Finasteride.

Inclusion criteria were a total IPSS $\geq 8$, $\mathrm{Q}_{\max }$ from $5 \mathrm{~mL} / \mathrm{s}$ to $15 \mathrm{~mL} / \mathrm{s}$ and the plateau response to the routine medical treatment of BPH.

Exclusion criteria included patients with history of refractory urinary retention, persistent gross hematuria, recurrent urinary tract infec- tion (UTI), renal insufficiency, bilateral hydronephrosis and bladder stones all secondary to BPH, spinal cord injury, prostatitis, bladder or prostate malignancy, bladder neck or urethral stricture, post voided residual urine volume greater than $120 \mathrm{CC}$, pelvic trauma or surgery, recent cardiac infarction (within the last 6 months), unstable angina, concomitant use of nitrates or NO donors, and androgens or anti-androgens, anticoagulants, cytochrome p-450 3A4 inhibitors. Also, if any complication occurred during the study period that needed surgical intervention, the patient was excluded from the study.

Complete history and physical examination, urine analysis, serum creatinine measurement, as well as ultrasonography of kidney, bladder and prostate with post voided residual urine volume measurement; uroflowmetry with measurement of the maximum flow rate $\left(Q_{\max }\right)$ and the assessment of quality of life (QoL) (Table-1) were performed. Then, the selected patients were randomized in two groups (66 patients in each group) by using random block method generated by Excell program. One group received placebo once nightly and another group received Tadalafil 10 $\mathrm{mg}$ nightly, in combination with previous treatment of BPH for 3 months. After 3 months, IPSS, $\mathrm{Q}_{\max }$, post voided residual urine volume and quality of life score were determined again.

Furthermore, during the study period, the adverse effects including orthostatic hypotension, headache, flushing, lumbar pain and gastrointestinal complaints were recorded. All patients were evaluated 6 weeks after the beginning of the study and the side effects were assessed as well.

Statistical analysis was performed using SPSS version 16 with paired T-Test, independent

Table 1 - Assessment of quality of life in order to quantify urinary problems.

\begin{tabular}{|c|c|c|c|c|c|c|}
\hline \multicolumn{7}{|c|}{ Quality of life due to urinary problems } \\
\hline Delighted & Pleased & Mostly satisfied & $\begin{array}{l}\text { Mixed-about equally satisfied } \\
\text { and dissatisfied }\end{array}$ & Mostly dissatisfied & Unhappy & Terrible \\
\hline 0 & 1 & 2 & 3 & 4 & 5 & 6 \\
\hline
\end{tabular}


T-Test, Wilcoxon signed ranks test, and MannWhitney test. $\mathrm{P}<0.05$ was considered significant.

This study was approved by the ethical review committee of Guilan University of Medical Science and the trial registered at IRCT.IR (IRCT201008094541N1).

\section{RESULTS}

Based on inclusion and exclusion criteria, 132 patients were selected randomly in two groups (66 patients in each group). Mean ages of patients were $64.4 \pm 10.33$ years in the treatment group and $64.87 \pm 9.20$ years in the placebo group. Mean prostate volume was $40.29 \mathrm{CC} \pm 11.18 \mathrm{CC}$ in the treatment group and $42.22 \mathrm{CC} \pm 12.38 \mathrm{CC}$ in the placebo group. There was no significant difference in the IPSS, post voided residual urine volume, $Q_{\max }$ and quality of life score (baseline characteristics) before treatment between the two groups.

After treatment, in relation to the beginning of the study, the placebo group showed reduction of mean IPSS statistically significant. The mean post voided residual urine volume increased but was not statistically significant. The mean QoL score decreased and was statistically significant. The mean $Q_{\max }$ decreased but it was not statistically significant (Table-2). creased and the difference was statistically significant (Table-3).

At the end of study, in relation to the beginning of the study, the mean IPSS was $7.66 \pm$ 3.99 and $11.37 \pm 3.64$ in the treatment and placebo groups, respectively. The mean $\mathrm{Q}_{\max }$ was 9.99 $\pm 4.76 \mathrm{~mL} / \mathrm{s}$ and $8.73 \pm 2.22 \mathrm{~mL} / \mathrm{s}$ in the treatment and placebo groups, respectively. The mean quality of life score was $1.8 \pm 0.98$, and $2.19 \pm 0.53$ in the treatment and placebo group, respectively. The mean post voided residual volume was 22.13 $\pm 21.65 \mathrm{~mL}$ and $26.91 \pm 23.17 \mathrm{~mL}$ in the treatment and placebo group, respectively (Table-4).

The side effects of Tadalafil included orthostatic hypotension, headache or flushing, lumbar pain and the side effects of placebo included gastrointestinal complaints. 9.1\% of patients from the treatment group and $6.1 \%$ of patients from the placebo group dropped out of study due to drug intolerance.

\section{DISCUSSION}

Lower urinary tract symptoms (LUTS) encompass all urinary symptoms such as storage, voiding and postmicturation symptoms. LUTS in men may be related to bladder outlet obstruction (B00) which is often associated with benign pros-

Table 2 - Mean values of variables before and after treatment of the placebo group.

\begin{tabular}{lccc}
\hline & Before & After & P-value \\
\hline IPSS & $13.66 \pm 4.25$ & $11.37 \pm 3.64$ & 0.001 \\
Residual Urine volume & $26.87 \pm 23.85$ & $26.91 \pm 23.17$ & 0.86 \\
Quality of life & $2.66 \pm 0.78$ & $2.19 \pm 0.53$ & $* 0.001$ \\
$Q_{\max }$ & $9.09 \pm 2.91$ & $8.73 \pm 2.22$ & 0.308 \\
\hline
\end{tabular}

*Wilcoxon Signed Ranks Test

After treatment, in relation to the beginning of the study, in the treatment group the mean IPSS and QoL score decreased, a difference that was statistically significant. The mean $Q_{\max }$ increased but it was not statistically significant. The mean post voided residual urine volume de- tatic hyperplasia (BPH) in about 50\% of men over 50 year with increasing prevalence up to $90 \%$ in those older than 80 year. Moreover, 25 to $50 \%$ of men with histologically confirmed BPH have LUTS (3). Likewise, male LUTS may result from bladder dysfunction or overactive bladder (OAB) (9). Epi- 
Table 3 - Mean values of variables before and after treatment of the drug group.

\begin{tabular}{lccc}
\hline & Before & After & P-value \\
\hline IPSS & $13.06 \pm(4.38)$ & $7.66 \pm(3.99)$ & 0.001 \\
Residual Urine volume & $24.53 \pm(25.75)$ & $22.13 \pm(21.65)$ & 0.002 \\
Quality of life & $2.93 \pm(0.86)$ & $1.80 \pm(0.98)$ & $* 0.001$ \\
$Q_{\max }$ & $8.92 \pm(2.96)$ & $9.99 \pm(4.76)$ & 0.06 \\
\hline
\end{tabular}

*Wilcoxon Signed Ranks Test

Table 4 - Mean values after treatment of the two groups.

\begin{tabular}{llll}
\hline & $\begin{array}{l}\text { Placebo } \\
\mathrm{n}=62\end{array}$ & $\begin{array}{l}\text { Drug } \\
\mathrm{n}=60\end{array}$ & P-value \\
\hline IPSS & $11.37 \pm(3.64)$ & $7.66 \pm(3.99)$ & 0.001 \\
Residual Urine volume & $26.91 \pm(23.17)$ & $22.13 \pm(21.65)$ & 0.241 \\
Quality of life & $2.19 \pm(0.53)$ & $1.8 \pm(0.98)$ & $* 0.036$ \\
$Q_{\max }$ & $8.73 \pm(2.22)$ & $9.99 \pm(4.76)$ & 0.066
\end{tabular}

*Mann-Whitney Test

demiological evidence provides a clear and clinically meaningful association between LUTS and various types of sexual dysfunction in aging men worldwide. The result of a longitudinal population based study of 428 Brazilian men without ED at baseline indicates that the adjusted relative risk of developing ED is 3.67 for those with self-reported BPH after a mean follow up of 2 years (10).

Pathophysiology of LUTS and sexual dysfunction, particularly ED and $\mathrm{EjD}$, has suggested some common components that may be involved. The prostate gland contains both epithelial and stromal components; excessive growth of either or both components, increase smooth muscle tone in the prostate capsule and the bladder neck can also contribute to the LUTS associated with BPH. Although the pathophysiology of LUTS associated with BPH was historically attributed to prostate gland enlargement and bladder outlet obstruction, the weak correlation between LUTS and prostate size $(10,11)$ has resulted in a greater focus on the role of increase muscle tone in the prostate and bladder and highlighted the need to investigate other possible underlying mechanisms. Increase smooth muscle tone in the prostate with BPH is related to the stimulation of $\alpha 1$-adrenergic receptors (12).

Other receptors which have been identified in human prostate tissue may play a role in LUTS associated with BPH, including dopaminergic, muscarinic, serotoninergic and histaminergic receptors (13). Nitric oxide (NO) which is present in the human prostate (14) and modulates prostatic smooth muscle tone (15) may also play a role in the pathophysiology of LUTS associated with BPH. Although the precise mechanism of action by which PDE- 5 inhibitors may alleviate LUTS is not completely understood, several putative mechanisms are currently under investigation.

One mechanism focuses on the accumulation of intracellular prostatic and bladder smooth muscle cyclic guanosine monophosphate following PDE-5 inhibition which may decrease tension of the smooth muscle of the prostatic stroma and 
capsule. This muscle relaxation results in bladder neck opening and improved voiding function (16).

Another possible mechanism involves pelvic arterial insufficiency and ischemia, which may compromises normal bladder detrusor function that causes a change in prostatic structure $(17,18)$. Increased vascular perfusion of the lower urinary tract especially the prostate or bladder neck can result in a beneficial therapeutic effect and decrease LUTS (19).

Additional theories about PDE-5 inhibition of the lower urinary tract suggest that LUTS decrease via modification of afferent nerve signaling from the bladder and urethra (20).

In the study (21) by McVary et al., following a 4-week period, single-blind, placebo run-in 281 men were randomly assigned (1:1) to $5 \mathrm{mg}$ Tadalafil for 6 weeks, followed by dose titration to $20 \mathrm{mg}$ for 6 weeks, or 12 weeks of placebo. In their study, Tadalafil significantly improved the IPSS at 6 weeks and 12 weeks of the Tadalafil group. No change in post voided residual volume was reported. They concluded that Tadalafil once daily was well tolerated and demonstrated clinically meaningful and statistically significant symptomatic improvement of lower urinary tract symptoms/benign prostatic hyperplasia. Tadalafil also improved erectile function in men with lower urinary tract symptoms and erectile dysfunction. Of the doses studied, $5 \mathrm{mg}$ Tadalafil appeared to provide a positive risk-benefit profile. Treatment adverse side effects included dyspepsia, back pain, headache, nasopharyngitis and upper respiratory tract infection. In the current study, 6 patients experienced adverse side effects such as orthostatic hypotension, headache or lumbar pain in the treatment group and 2 patients experienced the gastrointestinal upsets in the placebo group.

In another study (22), during a 12 week study period, 369 men with ED and LUTS (IPSS > 12 , mean age of 50 years) received Sildenafil $50 \mathrm{mg}$ daily or placebo. Results showed that Sildenafil significantly improved IPSS and quality of life scores. Interestingly, there was no change in maximum flow rate.

In the study by Stief et al. (23), men aged 45-64 years with BPH/LUTS and an IPSS > 12 were randomized to receive either $10 \mathrm{mg}$ Vardenafil or placebo twice daily. After 8 weeks of treatment, there was a significant improvement in the IPSS total score in the Vardenafil group compared to placebo ( -5.9 and -3.6 , respectively; $\mathrm{p}=0.0013$ ). Nominally significant improvements in irritative and obstructive IPSS subscores $(p=0.0017$ and $p$ $=0.0081$, respectively), EF (Erectile function) ( $p=$ 0.0001), and Urolife QoL-9 ( $p<0.0001)$ were also associated with Vardenafil treatment. $Q_{\max }$ and PVR urine volume did not change significantly with treatment, although baseline values were already considered close to normal. Vardenafil was generally well tolerated, with most adverse events considered mild or moderate in severity. They concluded that Vardenafil treatment significantly improved LUTS, EF, and QoL in men with BPH/LUTS and Vardenafil may be considered a promising treatment option for men with symptoms secondary to BPH.

In the study by Broderick et al. (24), men with moderate-to-severe BPH-LUTS who received placebo for 4 weeks, were randomized to placebo or Tadalafil 2.5, 5, 10, or $20 \mathrm{mg}$ once daily for 12 weeks. At the end of treatment, changes in IPSS in men with ED and without ED were evaluated and were not significantly different. Changes in IPSS, quality of life and BPH Impact Index were similar in 2 groups. Tadalafil was generally well tolerated in men with or without ED. They concluded that changes in BPH-LUTS in placebo and Tadalafil groups were similar in men with or without comorbid ED.

In another study by Kim et al. (25), men with an International Index of Erectile Function-5 (IIEF-5) score of less than 11 and with an IPSS of more than 8 were included for treatment with 20 mg Tadalafil (once every 3 days) for 12 weeks. Changes in IPSS and IIEF- 5 scores were significant different between baseline and end of treatment. Furthermore, the differences of these scores were significant between baseline and week 20 after treatment. However, except for IIEF-5 scores, there were no significant differences between week 12 and week 20. They concluded that treatment with tadalafil were effective on LUTS and ED in patients with moderate-to-severe ED and LUTS.

Mirone et al. (26) reported the first comparative trial of alternative dosing, investigating treatment efficacy and patient preference for 20 
mg Tadalafil taken on-demand versus 3 times per week, over a 6 -weeks study period for the treatment of ED. This study demonstrated that $42.2 \%$ of men preferred scheduled dosing versus 57.8\% for on-demand; both treatment regimens were well tolerated and successful.

More recent studies have demonstrated that constant doses may be advantageous versus on-demand regimens, offering a valuable treatment option for ED.

McMahon (27) reported upon the efficacy, safety, and tolerability of on-demand $20 \mathrm{mg}$ versus daily dosed $10 \mathrm{mg}$ Tadalafil in 145 men with mild to severe ED of various etiologies in a 26 weeks study period. Patients receiving on-demand and daily Tadalafil experienced a significant mean improvement of 8.3 and 11.9 points in the IIEF, respectively ( $p<0.001$ ), with daily-dose mean changes significantly higher versus on-demand Tadalafil ( $\mathrm{p}<$ 0.05). Successful completion of sexual intercourse was also statistically higher for daily Tadalafil than for on-demand Tadalafil $(\mathrm{p}<0.05)$. Also, both treatments were well tolerated. The authors concluded that treatment with daily Tadalafil was associated with a significantly higher IIEF erectile function domain score and completion of successful intercourse compared with on-demand Tadalafil (28).

In the current study, although Tadafil effect on ED and quality of erection was not assessed, the addition of $10 \mathrm{mg}$ Tadalafil once nightly for 3 months in patients whose symptoms had reached the plateau level with previous treatment with an $\alpha 1$-blocker and/or Finasteride was superior to placebo in improvement of IPSS and QoL. Although post void residual urine decreased and $\mathrm{Q}_{\max }$ increased with $10 \mathrm{mg}$ Tadalafil once nightly, the difference was not statistically significant. The lack of a significant peak flow improvement in men with LUTS suggestive of BPH treated with Tadalafil confirms the previous reports of PDE- 5 inhibitors compounds on $Q_{\max }$ as mentioned above.

\section{CONCLUSIONS}

Tadalafil improves quality of life and urinary symptoms subjectively in BPH patients but does not have significant effect on $Q_{\max }$. Therefore, considering the high prevalence of ED in this age group, this drug may be used in combination with standard medical therapies of BPH. However, further studies with larger samples are needed to document these findings.

\section{CONFLICT OF INTEREST}

None declared.

\section{REFERENCES}

1. Claus G. Rohrborn, John D. Mc Connell: Benign prostatic hyperplasia: Etiology, Pathophysiology, Epidemiology and Natural History In: Kavoussi, Novick, Patrin, Peters. Campbell-Walsh Urology. V.3. qth ed. SAUNDERS. 2007: pp. 2727-65.

2. Bacon CG, Mittleman MA, Kawachi I, Giovannucci E, Glasser DB, Rimm EB: Sexual function in men older than 50 years of age: results from the health professionals followup study. Ann Intern Med. 2003; 139: 161-8.

3. Chapple CR, Roehrborn CG: A shifted paradigm for the further understanding, evaluation, and treatment of lower urinary tract symptoms in men: focus on the bladder. Eur Urol. 2006; 49: 651-8.

4. Schiff JD, Mulhall JP: The link between LUTS and ED: clinical and basic science evidence. J Androl. 2004; 25: 470-8.

5. Joseph C, Presti Jr.: Neoplasms of the Prostate Gand. In: Tanagho EA, McAnich JW, (ed.), Smith's General Urology. 6th. New York, McGraw-Hill, 2004: p. 371-2.

6. Tinel H, Stelte-Ludwig B, Hütter J, Sandner P: Pre-clinical evidence for the use of phosphodiesterase-5 inhibitors for treating benign prostatic hyperplasia and lower urinary tract symptoms. BJU Int. 2006; 98: 1259-63.

7. Filippi S, Morelli A, Sandner P, Fibbi B, Mancina R, Marini $M$, et al.: Characterization and functional role of androgendependent PDE5 activity in the bladder. Endocrinology. 2007; 148: 1019-29.

8. Sairam K, Kulinskaya E, McNicholas TA, Boustead GB, Hanbury DC: Sildenafil influences lower urinary tract symptoms. BJU Int. 2002; 90: 836-9.

9. Giuliano F: Phosphodiesterase type 5 inhibitors improve male lower urinary tract symptoms. Eur Urol. 2008; 53: 1121-3; discussion 1123-4.

10. Moreira ED Jr, Lbo CF, Diament A, Nicolosi A, Glasser DB: Incidence of erectile dysfunction in men 40 to 69 years old: results from a population-based cohort study in Brazil. Urology. 2003; 61: 431-6.

11. Bosch JL, Kranse R, van Mastrigt R, Schröder FH: Reasons for the weak correlation between prostate volume and urethral resistance parameters in patients with prostatism. J Urol. 1995; 153: 689-93. 
12. Andersson KE: Alpha-adrenoceptors and benign prostatic hyperplasia: basic principles for treatment with alpha-adrenoceptor antagonists. World J Urol. 2002; 19: 390-6.

13. Kester RR, Mooppan UM, Gousse AE, Alver JE, Gintautas J, Gulmi FA, et al.: Pharmacological characterization of isolated human prostate. J Urol. 2003; 170: 1032-8. Erratum in: J Urol. 2003; 170: 2394.

14. Burnett AL, Maguire MP, Chamness SL, Ricker DD, Takeda $\mathrm{M}$, Lepor $\mathrm{H}$, et al.: Characterization and localization of nitric oxide synthase in the human prostate. Urology. 1995; 45: 435-9.

15. Takeda M, Tang R, Shapiro E, Burnett AL, Lepor H: Effects of nitric oxide on human and canine prostates. Urology. 1995; 45: 440-6.

16. Uckert $S$, Küthe $A$, Jonas U, Stief CG: Characterization and functional relevance of cyclic nucleotide phosphodiesterase isoenzymes of the human prostate. J Urol. 2001; 166: 2484-90.

17. Azadzoi KM, Babayan RK, Kozlowski R, Siroky MB: Chronic ischemia increases prostatic smooth muscle contraction in the rabbit. J Urol. 2003; 170: 659-63.

18. Berger AP, Deibl M, Leonhartsberger N, Bektic J, Horninger W, Fritsche G, et al.: Vascular damage as a risk factor for benign prostatic hyperplasia and erectile dysfunction. BJU Int. 2005; 96: 1073-8.

19. Pinggera GM, Mitterberger M, Pallwein L, Schuster A, Herwig $\mathrm{R}$, Frauscher $\mathrm{F}$, et al.: Alpha-Blockers improve chronic ischaemia of the lower urinary tract in patients with lower urinary tract symptoms. BJU Int. 2008; 101: 319-24.

20. Andersson KE, Uckert S, Stief C, Hedlund P: Phosphodiesterases (PDEs) and PDE inhibitors for treatment of LUTS. Neurourol Urodyn. 2007; 26(6 Suppl): 928-33.

21. McVary KT, Roehrborn CG, Kaminetsky JC, Auerbach SM, Wachs B, Young JM, et al.: Tadalafil relieves lower urinary tract symptoms secondary to benign prostatic hyperplasia. J Urol. 2007; 177: 1401-7.

22. McVary KT, Monnig W, Camps JL Jr, Young JM, Tseng LJ, van den Ende G: Sildenafil citrate improves erectile function and urinary symptoms in men with erectile dysfunction and lower urinary tract symptoms associated with benign prostatic hyperplasia: a randomized, double-blind trial. J Urol. 2007; 177: 1071-7.
23. Stief CG, Porst $H$, Neuser D, Beneke $M$, Ulbrich E: A randomised, placebo-controlled study to assess the efficacy of twice-daily vardenafil in the treatment of lower urinary tract symptoms secondary to benign prostatic hyperplasia. Eur Urol. 2008; 53: 1236-44.

24. Broderick GA, Brock GB, Roehrborn CG, Watts SD, ElionMboussa A, Viktrup L: Effects of tadalafil on lower urinary tract symptoms secondary to benign prostatic hyperplasia in men with or without erectile dysfunction. Urology. 2010 75: $1452-8$.

25. Kim TB, Kim KH, Yoon SJ: Open-label, Intermittent Dose, Prospective Study Evaluating the Effects of Tadalafil on Lower Urinary Tract Symptoms and Erectile Function in Patients with Benign Prostatic Hyperplasia: Continuation and Durability of Effects. Int Neurourol J. 2010; 14: 7-12.

26. Mirone V, Costa P, Damber JE, Holmes S, Moncada I, Van Ahlen $\mathrm{H}$, et al.: An evaluation of an alternative dosing regimen with tadalafil, 3 times/week, for men with erectile dysfunction: SURE study in 14 European countries. Eur Urol. 2005; 47: 846-54; discussion 854.

27. McMahon C: Comparison of efficacy, safety, and tolerability of on-demand tadalafil and daily dosed tadalafil for the treatment of erectile dysfunction. J Sex Med. 2005; 2: 41525; discussion 425-7.

28. Bella AJ, Deyoung LX, AI-Numi M, Brock GB: Daily administration of phosphodiesterase type 5 inhibitors for urological and nonurological indications. Eur Urol. 2007; 52: 990-1005. 